\title{
DETERMINATION OF DIFFUSION COEFFICIENT AND PERMEABILITY THROUGH THE BARRIER OF SUBSTANCE IN SIMULATED BIOMEDICAL SYSTEMS
}

\author{
Anna Adach ${ }^{*}$, Natalia Kister ${ }^{2}$, Andrzej Skassa ${ }^{1}$, Aleksandra Bugalska $^{1}$ \\ ${ }^{1}$ Warsaw University of Technology, Faculty of Chemical and Process Engineering, Waryńskiego 1, \\ 00-645 Warsaw, Poland \\ ${ }^{2}$ Warsaw University of Technology, Faculty of Chemistry, Noakowskiego 3, 00-645 Warsaw, \\ Poland
}

The investigations deal with mass transfer in simulated biomedical systems. The modification of classical diffusion chamber, sequential unit (SU) system, imitated different biomedical setups, boundary conditions. The experiments simulated: diffusion chamber (also with two barriers), transport through the membrane to the blood stream, transport from the stent eluting drug simultaneously to the vessel cells and to the blood stream. The concentrations of substances and the relative mass increases/decreases for SU systems indicate that the order of the curves follows the order of mass transfer resistances. The strong dependence of mass transfer rates versus type of diffusing substance was confirmed. The calculated drug fluxes, diffusion coefficients, permeation coefficients are convergent with literature. Permeation coefficients for complex sequential systems can be estimated as parallel connexion of constituent coefficients. Experiments approved functionality of the SU for investigations in a simulated biomedical system. Obtained data were used for numerical verification.

Keywords: drug release, substance transfer, diffusion chamber, biomedical systems

\section{INTRODUCTION}

Substance transport in biomedical systems applies to many processes in living organisms e.g. drug transport in tissues, the diffusion through biological membranes. In an ideal system, the drug would migrate to the proper organ quickly and in the optimal concentration (within therapeutic window), acting actively by the determined period of time, without any negative side effects and finally would be removed from organism. However, real processes undergoing in biomedical systems are very complex and it is difficult to obtain such a perfect scheme. Therefore experimental tests and studies on mathematical model simulations are carried out simultaneously for determining the drug transfer in such systems, which would help in predicting and controlling drug release.

The basic mechanism of mass transport in biomedical systems is diffusion in porous bodies or liquids, and transport by selective membranes. Previously designed systems were applied in Franz cells (Franz, 1975) and Ussing chambers (Ussing, 1947). Nowadays there are several methods of determining drug transfer in biomedical systems (Siepmann and Siepmann, 2008; Siepmann and Siepmann, 2012). The classical diffusion chamber is built of two chambers (donor and acceptor ones) separated by a membrane or another mass transfer barrier. The ideal mixing in both chambers allows to determine the diffusion coefficient by the membrane or/and the mass transfer rate (Bartosova and Bajgar, 2012; Cu 
and Saltzman, 2009; Desai and Vadgama, 1991). The submerged chamber acts analogically, however the donor chamber is immersed in a bigger acceptor chamber, through which the pure dissolvent flows (Addicks et al., 1987). Another modification is the dialysis sac method (or reversed dialysis) in which the dissolved drug fulfils the internal of the sac, while the concentration of the substance is measured in the circulating fluid (Lovich et al., 1998). Diffusion through the medium can also be determined by the so-called "infinite layer" method. The layer of active substance or its concentrated solution is contacted with the "mass transfer barrier", e.g. hydrogel of much bigger dimension. After a certain period of time the concentration of drug can be evaluated in the thin sliced layers of "barrier". Due to the conditions, the process is considered as unsteady, one-dimensional transport ( $\mathrm{Cu}$ and Saltzman, 2009). Noninvasive methods allow determining of diffusion rate without intervention in the experimental system (e.g. without the destruction of sample or probing). The methods consist of the radioactive or fluorescent particle cracking. The feedback from experiments is very convenient but modification of active substances molecules is necessary ( $\mathrm{Cu}$ and Saltzman, 2009; Groo and Lagarce, 2014). Substances like proteins or DNA can be traced using holographic interferometry and the phenomenon of light dispersion, diffusion of substances in gels can be determined by NMR spectroscopy. Spectroscopy FC or FRAP are used for visualization of transport of fluorescently tagged viruses, proteins, peptides or polymer nanoparticles in different media ( $\mathrm{Cu}$ and Saltzman, 2009; Groo and Lagarce, 2014).

The aim of research was to investigate active substance migration in simulated biomedical systems with the use of a self-designed experimental Sequential Unit system. The arrangements were to imitate mass transfer in different natural conformations. The parameters characterizing mass transfer in examined systems were to be obtained: diffusion coefficients, rates of diffusion, permeation coefficients.

\section{EXPERIMENTS WITH SEQUENTIAL UNIT}

The structure of the Sequential Unit (SU) is a self-designed modification of the classical diffusion chamber described above. The unique attribute of SU is the possibility of optional mounting of several modules made of acrylic glass, of different dimensions (cylindrical shape), which can be jointed in "parallel" sets. The unit, depending on the conducted experiment consisted of a donor chamber (with the examined medium), an acceptor chamber, a flow chamber etc. The units are bounded by medium or membrane constituting a mass transfer "barrier". Therefore many various geometrical combinations can be constructed, which could simulate different biomedical systems. This enables to determine mass transfer of the active substance under diverse initial and boundary conditions and process parameters (e.g. viscosity).

\subsection{Sequential Unit system SU1}

In the simplest setup, similar to Diffusion Chamber, the dissolved drug is transported from the donor chamber through the membrane (or other mass transfer barrier) to the acceptor chamber. The solutions in both chambers are mixed. The mass transfer barrier is mechanically supported and divided from the solutions by membranes characterized by great permeability and small mass transfer resistances. The concentration of substance in both units can be measured in proper periods of time. Diffusion coefficient can be determined using Diffusion Chamber in two ways. The known drug concentrations in the acceptor and donor chamber enable to calculate the substance flux and therefore the diffusion coefficient. The value of this coefficient can also be obtained according to lag time, i.e. when drug appears in the acceptor chamber ( $\mathrm{Cu}$ and Saltzman, 2009). This setup corresponds to a biomedical system in which the active ingredient is contacted directly with the organ to which it is transported. 
This arrangement allows to determine diffusion coefficients as well as permeation coefficients through the media constituting mass transfer barriers. Thanks to the fragmented construction of SU, the migration of the active substance in simulated complex systems e.g. through two (or more) media being mass transfer barriers can also be studied.

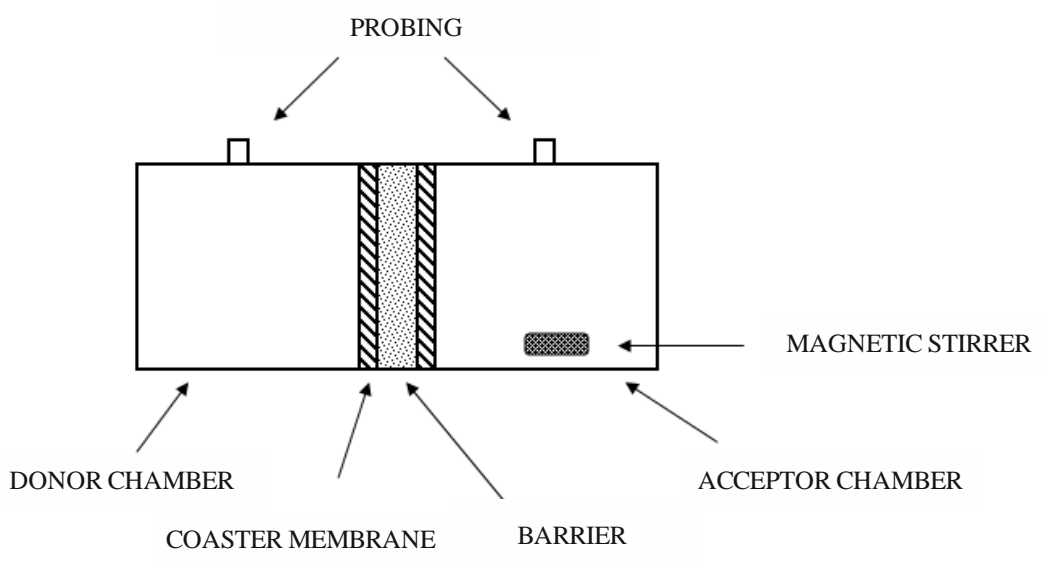

Fig. 1. SU1: Sequential Unit system, set up as Diffusion Chamber; diffusion through mass barrier e.g. membrane, hydrogel etc.

\subsection{Sequential Unit system SU2}

The next geometrical SU configuration consists of a donor chamber (with a solution of substance), mass transfer barrier and flow unit which the pure solvent flows through. The volumetric flow of liquid can be regulated. In the conducted experiments it was adjusted at the levels of blood flow in blood vessels.

Such conformations deal with the system, where the drug is transported from a dosing unit (donor chamber) through the biological membrane to the blood (flow unit $=$ acceptor chamber).

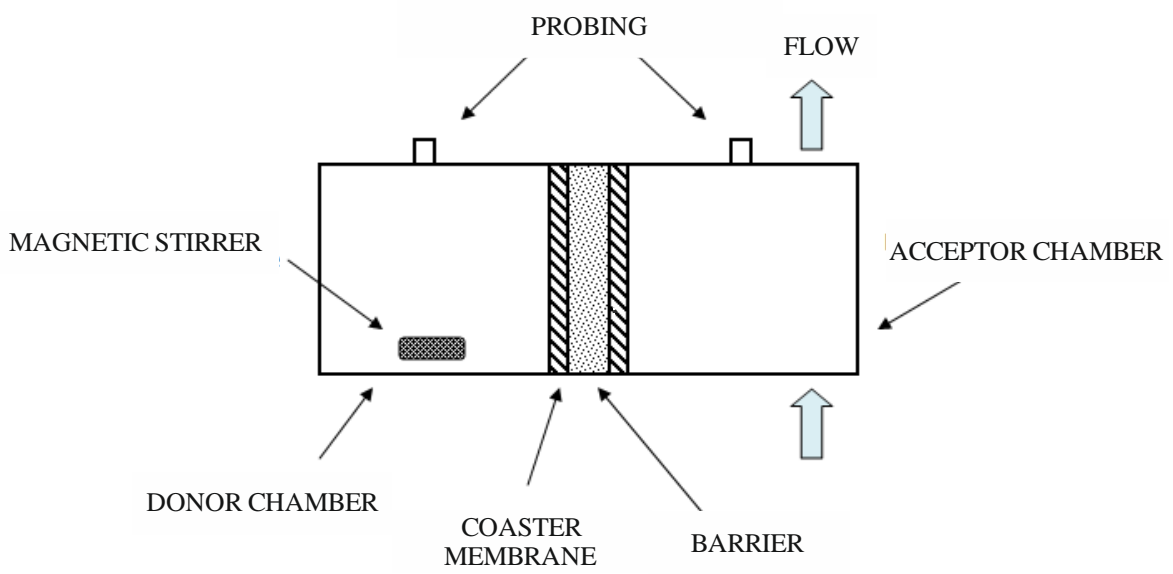

Fig. 2. SU2: Sequential Unit system with the flow chamber

\subsection{Sequential Unit system SU3}

The next system includes: a donor unit, a mass transfer barrier and a flow unit with recirculation. This system simulates the situation, when the substance transported to blood is accumulated in this liquid and is circulating internally in blood vessels (external reservoir). 
The above arrangement can respond also to the process of supplementation of drug circulating in blood vessels (solution of drug in external reservoir) to body organs.

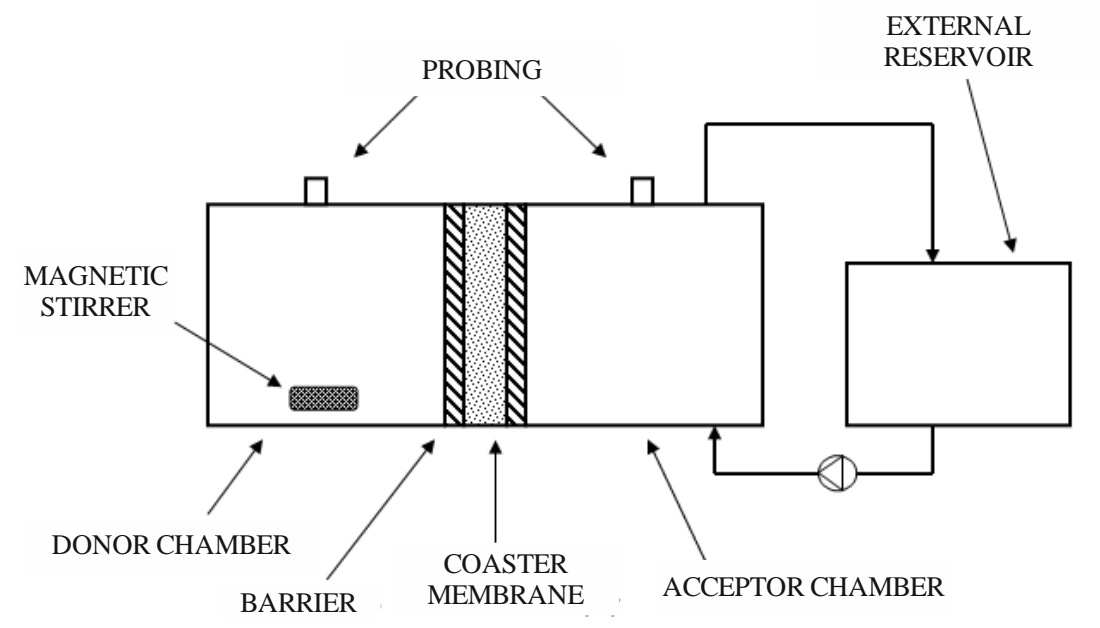

Fig. 3. SU3: Sequential Unit system with the flow chamber and recirculation

\subsection{Sequential Unit system SU4}

The system of SU presented below contains a donor chamber (with the solution of drug) located between the acceptor and flow units (with or without recirculation). The consecutive ventricles are separated by the following mass transfer barriers.

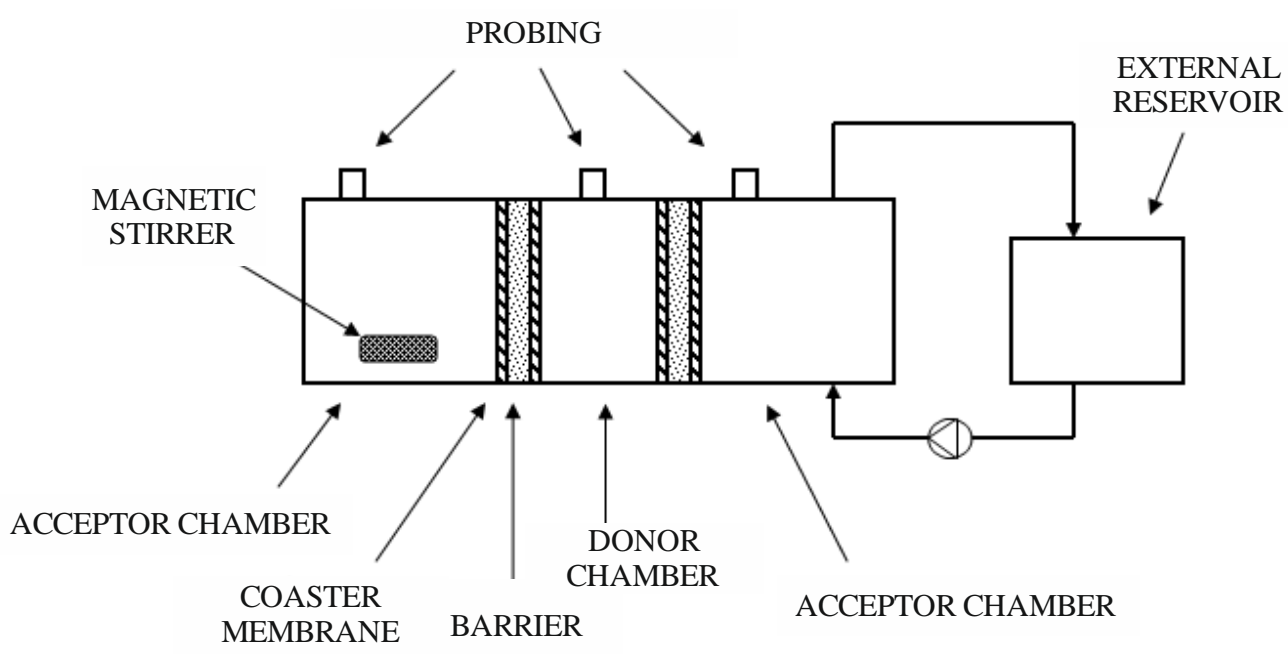

Fig. 4. SU4: Sequential Unit system imitating drug-eluting stent placed within the blood vessel

Stents implemented into blood vessels constitute a kind of scaffold for the sunken vessel. However, the use of stent frequently results in hyperplasia as a side effect (excessive increase of the amount of vessel cells), resulting in the thickening of arterial walls and decreased arterial lumen space.

The described geometry corresponds to the stent (with drug immobilized on it), inserted inside the blood vessel. While such situation occurs, the active substance deposited on the stent is simultaneously transported to the pellicle of the blood vessel (acceptor chamber) and swept away by the flowing blood (flow unit with circulation). Therefore the drug-eluting stents show promise with marked reduction in intimal hyperplasia compared to bare, metal stents. The above theme was the subject of investigations (Hirata et al., 2013; Kleinedler, 2012; Ziętek et al., 2013). 


\section{EXPERIMENTS}

Experiments were carried out in sequential systems described above. These different geometric configurations of $\mathrm{SU}$, in a simplified way, simulated processes of drug transport in various biomedical systems (Bugalska, 2015; Kister, 2015; Skassa, 2015).

The experiments differed from each other in several parameters. Substances used to simulate the active ingredient of drugs were: Cochineal Red A (Ponceau 4 R, Acid Red 18), Dopamine hydrochloride and Rhodamine B (Sigma Aldrich). Various concentrations of these substances were employed: from $0.01 \%$ mass. to $1 \%$ mass. Several media were examined as mass barrier in respective cases: gelatine as the simplest example of hydrogel, synthetic saliva and solutions of Sodium Carboxymethyl Cellulose $(\mathrm{CMCNa})$.

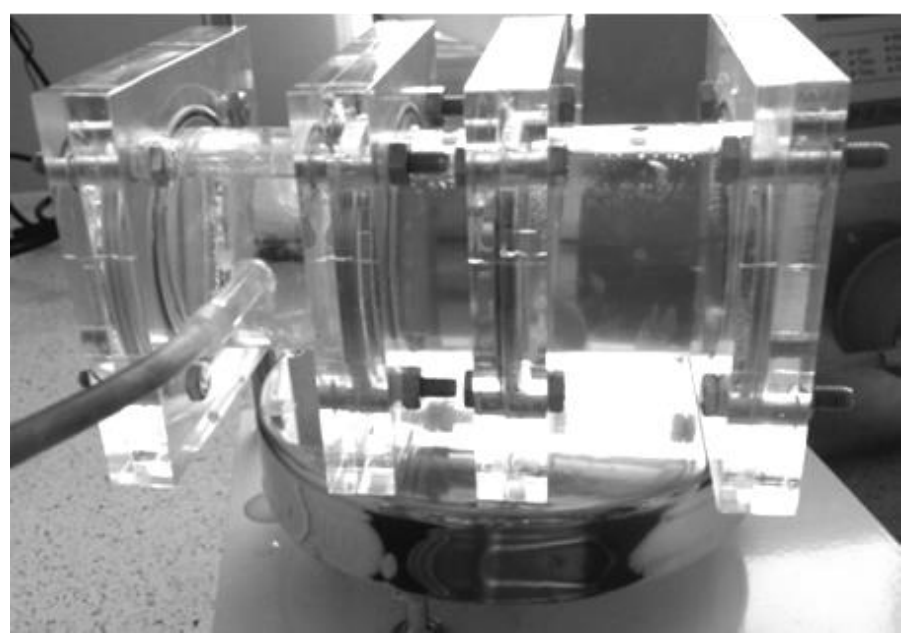

Fig. 5. The photograph of SU4 system

As „base”, mechanical coasters of hydrophilic PES membranes (Polyethersulphone Membranes) were used due to big permeability and small mass transport resistance (Pall Corporation).

Different volumetric flows of liquid in a flow unit were applied. Always, however, being within the scope of velocity of blood flow in blood vessels, volumetric flow range: $Q=83.5 \mathrm{~cm}^{3} / \mathrm{min}-300 \mathrm{~cm}^{3} / \mathrm{min}$. The influence of liquid viscosity on mass transfer was also studied using different $\mathrm{CMC}$ solutions.

Samples were analysed by spectrophotometry (Hitachi U-2900), studies were conducted in the range of a linear function of absorbance limited by $\mathrm{ABS}<2.5$, thus fulfilling the Lambert-Beer law. The calibration curves were used for examined active substances allowing to calculate percentage and molar concentration as a function of absorbance (Bugalska, 2015; Kister, 2015; Pawlak, 2013).

\section{ANALYSIS OF THE RESULTS}

The initial (total) mass of substance (donor chamber) was calculated as below:

$$
m_{0}=V_{D} \cdot c_{0} \cdot \frac{\rho_{r}}{100 \%}
$$

In acceptor chambers without the flow, mass of substance which migrated to this unit was calculated from the following equation:

$$
m_{a c c}=\frac{V_{A} \cdot \rho_{r} \cdot c_{A}}{100 \%}
$$


Mass of substance in the donor chamber in the given moment was computed from the measured values of absorbance (and therefore concentration) or as a difference between the total mass of substance and the mass which migrated to acceptor/flow chamber:

$$
\begin{gathered}
m_{d o n}=\frac{V_{D} \cdot \rho_{r} \cdot c_{A}}{100 \%} \\
m_{d o n}=m_{0}-m_{a c c} \text { or } m_{d o n}=m_{0}-m_{\text {flow }} \text { or } m_{d o n}=m_{0}-m_{\text {acc }}-m_{\text {flow }}
\end{gathered}
$$

Relative mass of drug respectively in acceptor/donor chambers was also evaluated:

$$
\begin{aligned}
\Delta m_{A} & =\frac{m_{a c c}}{m_{0}} \cdot 100 \% \\
\Delta m_{D} & =\frac{m_{d o n}}{m_{0}} \cdot 100 \%
\end{aligned}
$$

The mass of substance flowing out of SU system was calculated based on the current concentration of the drug in the flowing flux:

$$
m_{\text {flow }}=\frac{\int_{0}^{\mathrm{t}} c_{\text {flow }}(t) \cdot \rho_{r} Q d t}{100 \%}
$$

The total mass of substance in the SU systems with the external reservoir must fulfil the equation (for SU3 system):

$$
m_{\text {don }}+m_{\text {reserv }}=m_{0}-m_{a c c}
$$

or the formulation below for SU4 system:

$$
m_{\text {don }}+m_{\text {reserv }}=m_{0}-\left(m_{\text {acc } 1}+m_{\text {acc } 2}\right)
$$

The results of the investigations are presented in the form of graphs illustrating relative mass gain/loss of an active ingredient in the acceptor/donor compartment for exemplary systems. Strong dependence of mass transfer rates versus type of diffusing substance was shown in Fig. 6.

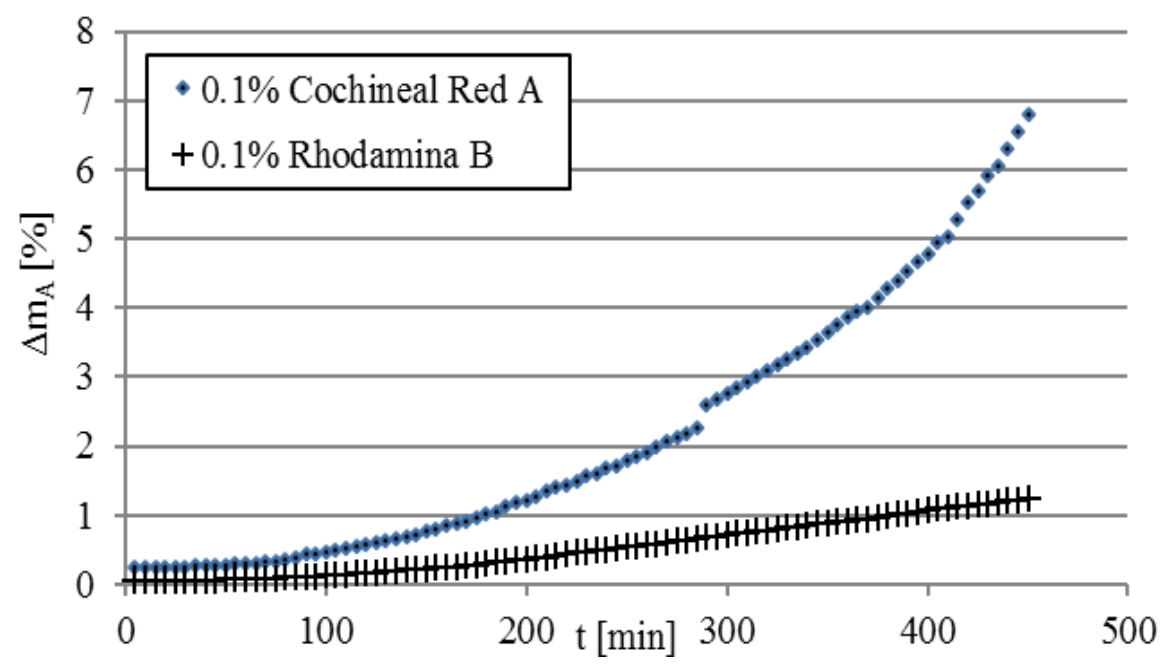

Fig. 6. The relative mass increase of substance in SU4 system (imitating stent) in acceptor chamber; diffusion through gelatin as mass transfer barrier

With an increase of the initial concentration of the active ingredients the mass transfer rate increased, due to the greater driving force of the process. The strong dependence of mass transfer rates versus concentration of diffusing substance was confirmed in the previous investigations (Bugalska, 2015; Kister, 2015; Skassa, 2015). 
One of the main factors that determines the rate of substance transport is the type of the barrier medium (Fig. 7). The rate of diffusion through the PES membrane was a few times greater than that of hydrogel. The diffusion rate significantly decreased when a solution of higher viscosity was used as a solvent (viscosity of $1 \%$ solution of $\mathrm{CMC}$ was $\mu=25[\mathrm{mPa} \cdot \mathrm{s}]$ while the viscosity of $2 \%$ solution of CMC was about $\mu=300[\mathrm{mPa} \cdot \mathrm{s}])$.

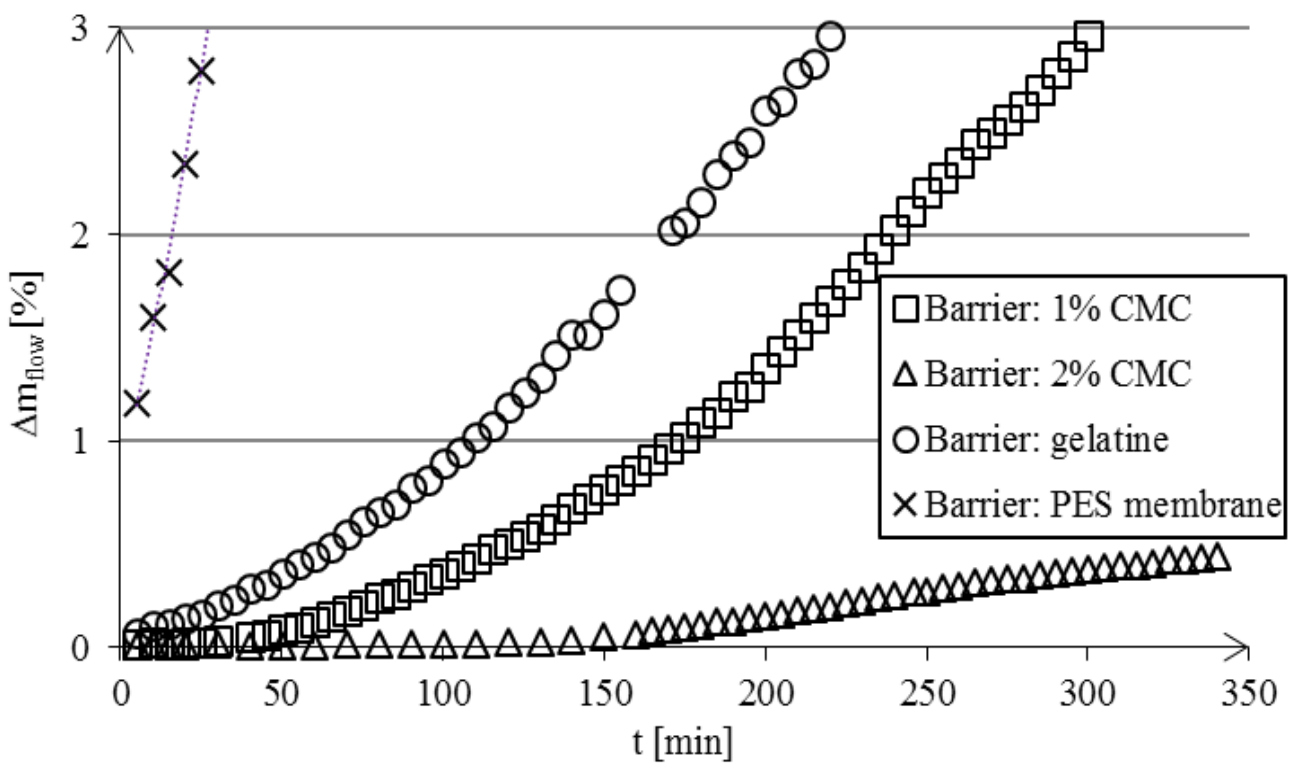

Fig. 7. The relative mass increase of substance in SU2 system (with flow) in acceptor chamber; diffusion through different mass transfer barriers, solution of Cochineal Red A (1\%)

The impact of the volume flow on propulsive force and speed of the process is noticeable in Fig. 8 . With increasing volumetric flow the mass transfer rate was growing.

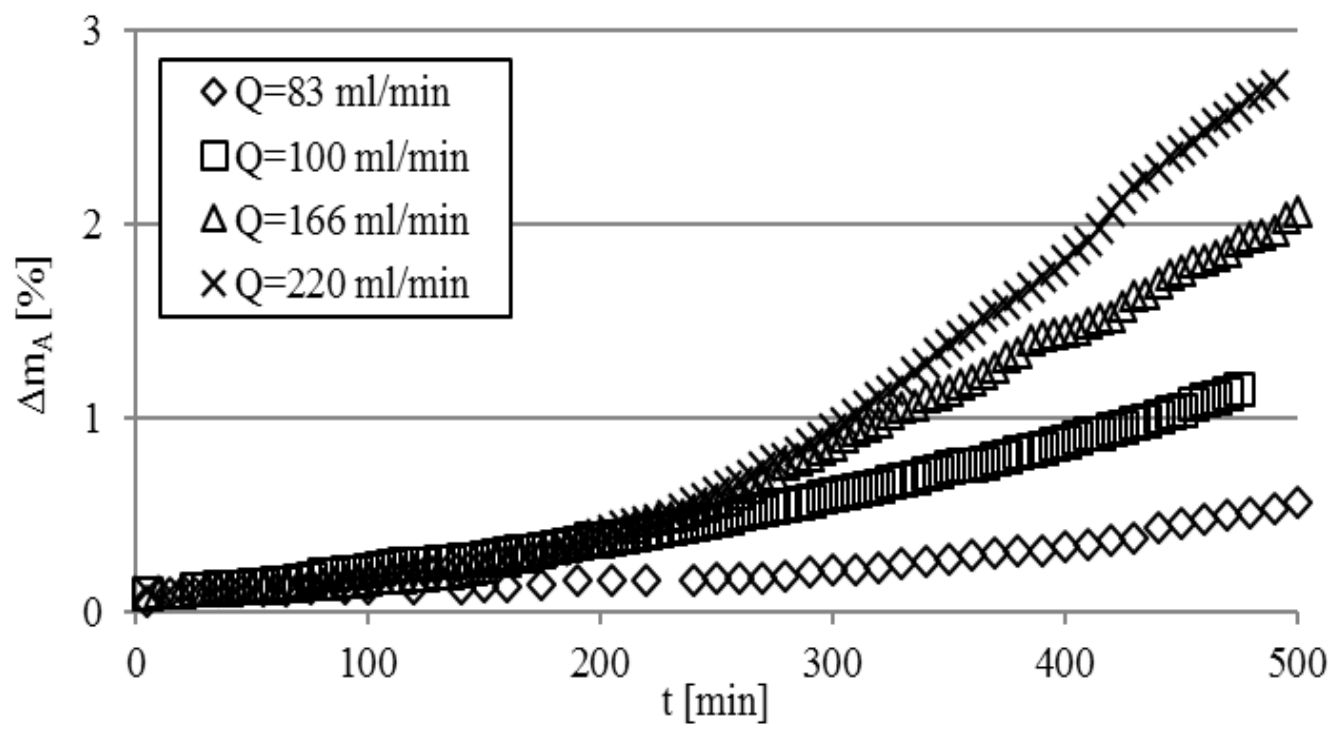

Fig. 8. The relative mass increase of substance in acceptor chamber in SU3 system (flow with recirculation); diffusion of Cochineal Red A $(0,03 \%)$ through gelatin as mass transfer barrier

The relative amounts of active substance used during experiments conducted in SU4 system (imitating stent) is illustrated in Fig. 9. 


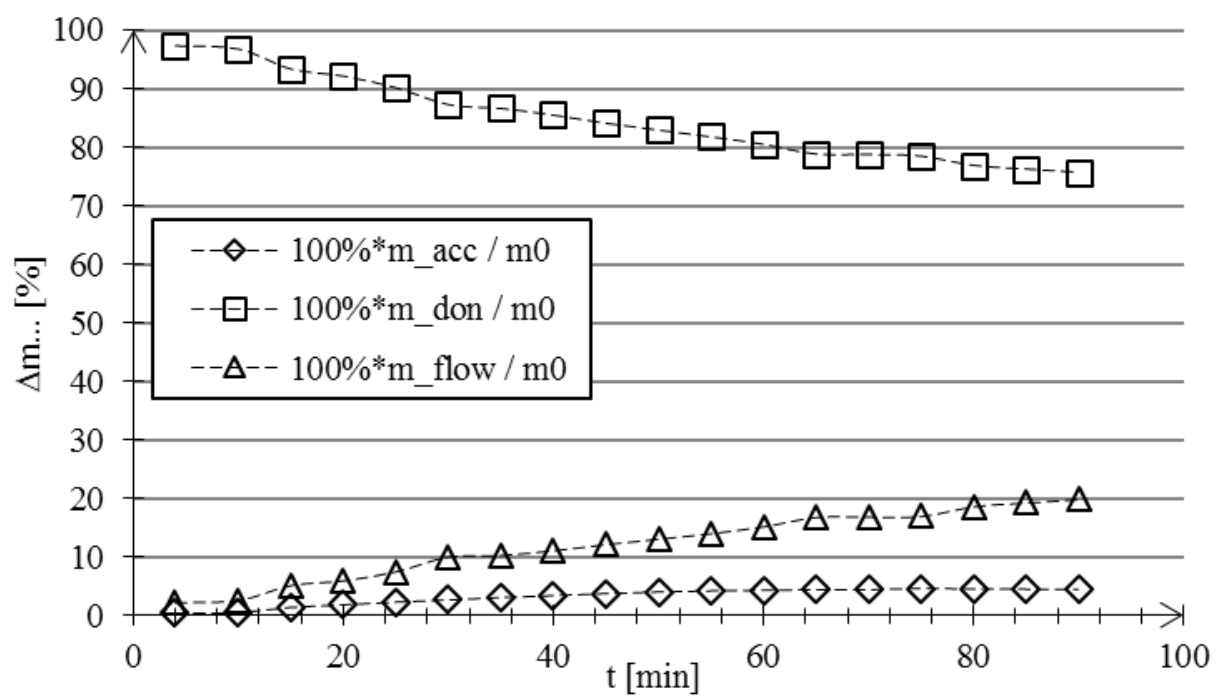

Fig. 9. The relative mass amounts of substance in chambers in adequate SU4 system (flow with recirculation); diffusion of Cochineal Red A (1\%) through gelatin as mass transfer barrier

The flux of an active substance A (per unit area) could be calculated from the equations:

$$
\begin{gathered}
J_{A}=\frac{\partial n}{\partial t \cdot A} \\
J_{A}=-D \frac{\partial c_{A}}{\partial x}
\end{gathered}
$$

The effective diffusion coefficients can be obtained as:

$$
D=-\frac{J_{A}}{\frac{\partial c_{A}}{\partial x}}
$$

The permeability coefficients $\kappa$ were evaluated:

$$
\kappa=\frac{J_{A}}{c_{A D}}
$$

The exemplary values of the calculated coefficients are listed below in Table 1 .

Table 1. Exemplary values of diffusion and permeability coefficients for different mass barrier media

\begin{tabular}{|c|c|c|c|c|}
\hline Substance & $\begin{array}{c}\text { Subst. molecular } \\
\text { mass }[\mathrm{g} / \mathrm{mol}]\end{array}$ & $\begin{array}{c}\text { Type of mass } \\
\text { barrier }\end{array}$ & $\begin{array}{c}\text { Diffusion coeff. } \\
D\left[\mathrm{~m}^{2} / \mathrm{s}\right]\end{array}$ & $\begin{array}{c}\text { Permeability } \\
\text { coeff. } \kappa[\mathrm{m} / \mathrm{s}]\end{array}$ \\
\hline $\begin{array}{c}\text { Dopamine } \\
\text { hydrochloride }\end{array}$ & 189.64 & Gelatin & $3.46 \times 10^{-11}$ & 0.42 \\
\hline Rhodamine B & 479.01 & Gelatin & $4.10 \times 10^{-12}$ & 0.29 \\
\hline Cochineal Red A & 604.47 & Gelatin & $7.62 \times 10^{-11}$ & 0.49 \\
\hline Cochineal Red A & 604.47 & Synthetic saliva & $7.19 \times 10^{-10}$ & 1.81 \\
\hline Cochineal Red A & 604.47 & CMC $0,5 \%$ & $6.85 \times 10^{-10}$ & 1.63 \\
\hline Cochineal Red A & 604.47 & CMC $1 \%$ & $6.25 \times 10^{-10}$ & 1.29 \\
\hline Cochineal Red A & 604.47 & CMC $2 \%$ & $2.51 \times 10^{-10}$ & 0.61 \\
\hline Cochineal Red A & 604.47 & CMC 3\% & $4.05 \times 10^{-11}$ & 0.097 \\
\hline Cochineal Red A & 604.47 & CMC $4 \%$ & $2.00 \times 10^{-11}$ & 0.051 \\
\hline
\end{tabular}


The obtained results were consistent with the literature data (Giannola et al., 2007; Ansari et al., 2006; Serra et al., 2006).

The calculations indicated that the permeation coefficients for complex sequential systems (e.g. two media being the mass transfer barriers) can be estimated as a sum of two constituent permeation coefficients connected in parallel:

$$
\frac{1}{\kappa_{1+2}}=\frac{1}{\kappa_{1}}+\frac{1}{\kappa_{2}}
$$

For example, the effective permeation coefficient for the complex SU1 system gelatine/synthetic saliva calculated from Eq. (14) resulted in $\kappa_{\text {gelat } / \text { saliva }}=0.3859 \mathrm{~m} / \mathrm{s}$ while the experimental permeation coefficient for the system where both gelatine and synthetic saliva constituted mass transfer barrier was $\kappa_{\text {gelat } / \mathrm{saliva}}=0.3488 \mathrm{~m} / \mathrm{s}$. Franke et al. (2000) also assumed that the total resistance of the system is additively composed of two parallel resistances: that of the cell monolayer and that of the filter. It should be underlined that Eq. (14) is valid when both mass transfer resistances are linear versus concentration.

The exemplary fluxes (per unit area) of an active substance given below were calculated at the steady state.

Table 2. Exemplary values of fluxes (per unit area) of active substance for different mass barrier media (molecular mass of Cochineal Red A is 604.47 [g/mol]).

\begin{tabular}{|c|c|c|}
\hline Substance & Type of mass barrier & $J_{A}[\mathrm{~mol} / \mathrm{m} 2 \mathrm{~s}]$ \\
\hline $0.01 \%$ solution of Cochineal Red A & gelatine & $1.10 \times 10^{-8}$ \\
\hline $0.03 \%$ solution of Cochineal Red A & gelatine & $1.83 \times 10^{-8}$ \\
\hline $0.10 \%$ solution of Cochineal Red A & gelatine & $6.20 \times 10^{-8}$ \\
\hline $0.25 \%$ solution of Cochineal Red A & gelatine & $2.85 \times 10^{-7}$ \\
\hline $1.00 \%$ solution of Cochineal Red A & gelatine & $1.24 \times 10^{-6}$ \\
\hline $1.00 \%$ solution of Cochineal Red A & CMC 1\% & $7.18 \times 10^{-7}$ \\
\hline $1.00 \%$ solution of Cochineal Red A & CMC 2\% & $2.12 \times 10^{-7}$ \\
\hline $1.00 \%$ solution of Cochineal Red A & CMC 3\% & $1.94 \times 10^{-8}$ \\
\hline $1.00 \%$ solution of Cochineal Red A & membrane PES & $1.15 \times 10^{-5}$ \\
\hline
\end{tabular}

The paper belongs to a wide range of studies on migration of substances in simulated biomedical systems. The results serve as an input values for numerical calculations (presented in another article).

\section{CONCLUSIONS}

The presented investigations concern mass transfer in simulated biomedical systems. An originally designed Sequential Unit (SU) system was set up. The unique attribute of SU is a possibility of the optional joining of different elements in sequential, "parallel" sets and therefore the migration of the active substance in simulated complex systems could be studied, imitating different biomedical conditions and various boundary conditions.

Apart from the diffusion investigations provided in a classical diffusion chamber, other unit sets, simulating different biomedical systems were analysed. The conducted experiments simulated e.g. the situation when the active substance migrates through the permeable membrane to the blood stream and 
is accumulated in the liquid (or is not, in other experiments). Another system simulated the situation when the active substance from the drug eluting stent was transported to the blood vessel cells and simultaneously was drifted by the blood stream. The substance migration from the donor chamber through at least two media (e.g. selective synthetic saliva/gelatine) to the pure solvent was also investigated. Experimental studies were performed with several biomedical media and active substances.

The substance concentrations in the chambers as a function of time as well as the relative mass increase for different SU systems indicate the correctness of the results. The order of the curves follows the order of mass transfer resistances. The issues confirm a strong dependence of the mass transfer rate versus type of diffusing substance while the influence of substance concentration was discussed in earlier works (Bugalska, 2015; Kister, 2015; Skassa, 2015).

The drug fluxes and the effective diffusion coefficients in the examined media were calculated as well as the permeation coefficients for different systems. The computed values of coefficients are in agreement with literature data. The calculations indicate that the permeation coefficients for the complex sequential systems (two media being the mass transfer resistances) can be estimated as a sum of two constituent permeation coefficients connected in parallel.

The conducted experiments confirmed the functionality of the sequential system for studying the mass transfer in simulated biomedical systems. The obtained data were used for the experimental verification of the mathematical model of the process.

The bases for this work have been carried out within the financial support of the National Science Centre Grant No. N N209 132640.

\section{SYMBOLS}

\begin{tabular}{|c|c|}
\hline$A$ & area of mass transfer, $\mathrm{m}^{2}$ \\
\hline$c$ & concentration of the diffusing substance, $\%_{\text {mass }}$ \\
\hline$c_{0}$ & initial concentration of the diffusing substance, $\%_{\text {mass }}$ \\
\hline$c_{A}$ & concentration of the diffusing substance, $\mathrm{mol} / \mathrm{dm}^{3}$ \\
\hline$c_{A D}$ & concentration of the diffusing substance in donor chamber, $\mathrm{mol} / \mathrm{dm}^{3}$ \\
\hline$c_{\text {flow }}(t)$ & concentration of the diffusing substance in flow unit, $\%$ mass \\
\hline$C_{M D}$ & concentration of the diffusing substance, $\mathrm{mol} / \mathrm{dm}^{3}$ \\
\hline$D$ & diffusion coefficient, $\mathrm{m}^{2} / \mathrm{s}$ \\
\hline$J_{A}$ & flux of substance A per unit area, $\mathrm{mol} /\left(\mathrm{m}^{2} \cdot \mathrm{s}\right)$ \\
\hline$M$ & molar mass of substance $\mathrm{A}, \mathrm{g} / \mathrm{mol}$ \\
\hline$m_{0}$ & initial (total) mass of the diffusing substance (donor chamber), $\mathrm{g}$ \\
\hline$\Delta m_{0}$ & relative increase of mass of the diffusing substance in acceptor chamber, $\%$ mass \\
\hline$m_{a c c}$ & mass of the diffusing substance in acceptor chamber, $g$ \\
\hline$m_{d o n}$ & mass of the diffusing substance in donor chamber, $g$ \\
\hline$\Delta m_{D}$ & relative decrease of mass of the diffusing substance in donor chamber, $\%_{\text {mass }}$ \\
\hline$m_{\text {flow }}$ & mass of the diffusing substance drifted from flow chamber, $g$ \\
\hline$m_{\text {reserv }}$ & mass of the diffusing substance in external reservoir, $g$ \\
\hline$n$ & number of moles of substance $\mathrm{A}, \mathrm{mol}$ \\
\hline$Q$ & volumetric flow of the solution, $\mathrm{dm}^{3} / \mathrm{s}$ \\
\hline$t$ & time, $\mathrm{s}$ \\
\hline$V_{A}$ & volume of the acceptor chamber, $\mathrm{dm}^{3}$ \\
\hline$V_{D}$ & volume of the donor chamber, $\mathrm{dm}^{3}$ \\
\hline
\end{tabular}


coordinate parallel to the diffusion flux direction, ranging from 0 to the mass barrier thickness, $\mathrm{m}$

\section{Greek symbols}

$\kappa \quad$ permeation coefficient, $\mathrm{m} / \mathrm{s}$

$\rho_{r} \quad$ density of solution, $\mathrm{g} / \mathrm{dm}^{3}$

\section{REFERENCES}

Addicks W.J., Flynn G.L., Weiner N., 1987. Validation of a flow-through diffusion cell for use in transdermal research. Pharm. Res., 4, 337-341. DOI: 10.1023/A:1016405506028.

Ansari M., Kazemipour M., Aklamli M., 2006. The study of drug permeation through natural membranes. Int. J. Pharm., 327, 6-11. DOI: 10.1016/j.ijpharm.2006.07.034.

Bartosowa L., Bajgar J., 2012. Transdermal drug delivery in vitro using diffusion cells. Curr. Med. Chem., 19, 4671-4677. DOI: $10.2174 / 092986712803306358$.

Bugalska A., 2015. Badanie szybkości migracji sktadnika aktywnego w symulowanych układach biomedycznych dla różnych warunków początkowych i brzegowych. MSc thesis, Warsaw University of Technology, Warsaw.

$\mathrm{Cu}$ Yen, Saltzman W. M., 2009. Mathematical modelling of molecular diffusion through mucus. Adv. Drug Delivery Rev., 61, 101-114. DOI: 10.1016/j.addr.2008.09.006.

Desai M.A., Vadgama P., 1991. Estimation of effective diffusion coefficients of model solutes through gastric mucus: assessment of a diffusion chamber technique based on spectrophotometric analysis. Analyst, 116, 11131116. DOI: 10.1039/AN9911601113.

Franke H., Galla H.J., Beuckmann C.T., 2000. Primary cultures of brain microvessel endothelial cells: a valid and flexible model to study drug transport through the blood-brain barrier in vitro. Brain Res. Protoc., 5, 248-256. DOI: $10.1016 / \mathrm{S} 1385-299 \mathrm{X}(00) 00020-9$.

Franz T. J., 1975. Percutaneous absorption on the relevance of in vitro data. J. Invest. Dermatol. 64(3), 190-195. DOI: 10.1111/1523-1747.ep12533356.

Giannola L.I., De Caro V., Giandalia G., Siragusa M.G., Campisi G., Florena A. M., Ciach T., 2007. Diffusion of naltrexone across reconstituted human oral epithelium and histomorphological features. Eur. J. Pharm. Biopharm., 65, 238-246. DOI: 10.1016/j.ejpb.2006.07.004.

Groo A.C., Lagarce F., 2014. Mucus models to evaluate nanomedicines for diffusion. Drug Discovery Today, 19, 1097-1108. DOI: 10.1016/j.drudis.2014.01.011.

Hirata, Y., Kurobe, H., Nishio, C., Tanaka, K., Fukuda, D., Uematsu, E., Nishimoto, S., Soeki, T., Harada, N., Sakaue, H., Kitagawa, T., Shimabukuro, M., Nakaya, Y., Sata, M., 2013. Exendin-4, a glucagon-like peptide-1 receptor agonist, attenuates neointimal hyperplasia after vascular injury. Eur. J. Pharmacol., 669, 106-111. DOI: 10.1016/j.ejphar.2012.11.057.

Kister N., 2015. Wyznaczanie szybkości dyfuzji w biomedycznych. MSc thesis, Warsaw University of Technology, Warsaw.

Kleinedler J.J., 2012. Novel nanocomposite stent coating releasing resveratrol and quercetin reduces neointimal hyperplasia and promotes re-endothelialization. J. Controlled Release, 125, 27-33. DOI: 10.1016/j.jconrel.2012.01.008.

Lovich M.A., Philbrook M., Sawyer S., Weselcouch E., Edelman E.R., 1998. Arterial heparin deposition: role of diffusion, convection, and extravascular space. American Journal of Physiology - Heart and Circulatory Physiology, 275 (6), 2054-2087.

Pawlak A., 2013. Badanie szybkości migracji substancji z dodatnich źródet masy. MSc thesis, Warsaw University of Technology, Warsaw.

Serra L., Domenech J., Peppas N.A., 2006. Drug transport mechanism and release kinetics from molecularly designed poly(acrylic acid-g-ethylene glycol) hydrogels. Biomaterials, 27, 5440-5451. DOI: 10.1016/j.biomaterials.2006.06.011.

Siepmann J., Siepmann F., 2008. Mathematical modelling of drug delivery (Review). Int. J. Pharm., 364, 328343. DOI: 10.1016/j.ijpharm.2008.09.004.

Siepmann J., Siepmann F., 2012. Modelling of diffusion controlled drug delivery. J. Controlled Release, 161, 351-362. DOI: 10.1016/j.jconrel.2011.10.006. 
Skassa A., 2015. Badanie szybkości migracji sktadnika aktywnego w symulowanych układach biomedycznych o różnych geometriach. MSc thesis, Warsaw University of Technology, Warsaw.

Ussing H. H. 1947. Interpretation of the exchange of radio-sodium in isolated muscle. Nature, 160, 262. DOI: 10.1038/160262a0.

Ziętek P., Butruk B., Ciach T., 2013. Endothelial cells adhesion on modified polyurethane surface as the way to fabricate a novel material for cardiosurgery, In: Santos R., Aldred N., Gorb S., Flammang P. (Eds.), Biological and biomimetic adhesives. Challenges and opportunities. RSC Publishing Cambridge, UK, 149-163. DOI: 10.1039/9781849737135-00149.

Received 07 April 2017

Received in revised form 09 November 2017

Accepted 10 November 2017 